\title{
Os sentidos do trabalho para egressos do sistema prisional inseridos no mercado formal de trabalho'
}

\author{
Isadora d'Ávila Toledo, ${ }^{2}$ Valéria Heloisa Kemp ${ }^{3}$ \\ e Marília Novais da Mata Machado ${ }^{4}$ \\ Universidade Federal de São João del Rei
}

Dados relativos a egressos do sistema prisional brasileiro mostram numerosas reincidências na infração à lei, acompanhadas por crescimento contínuo da população carcerária, geralmente exposta a condições precárias nas prisões. Nesse quadro, programas de inclusão social de egressos são importantes. Neste estudo, pesquisou-se o Projeto Regresso, desenvolvido em Minas Gerais, visando reintegrar o egresso ao mercado formal de trabalho, via organizações parceiras. Considerando que a atividade laboral tem uma função central na vida desse sujeito e utilizando como referencial teórico, entre outros, sobretudo os trabalhos de Morin, buscou-se compreender os sentidos atribuídos ao trabalho por egressos inseridos em duas organizações parceiras do Projeto Regresso. Como metodologia, adotou-se a pesquisa qualitativa. Os 12 egressos e os dois profissionais de RH das organizações foram entrevistados e suas falas transcritas. O material das entrevistas foi submetido à análise do conteúdo, o que levou à criação de seis categorias analíticas para a fala dos egressos - trajetória de trabalho, vida na prisão, vida pós-prisão, trabalhos como egressos, percepção do trabalho, sentidos do trabalho - e uma sétima, a visão dos profissionais de RH. Os resultados mostram que, paradoxalmente, apesar de exercerem atividades precárias, os egressos relatam satisfação no trabalho.

Palavras-chave: Sentidos do trabalho, Egresso do sistema prisional, Reinserção no mercado formal de trabalho.

The meanings of work for former convicts inserted in the formal labor market

Data about Brazilian former convicts show numerous recurrences of law violation, accompanied by the continued growth of the prison population, often exposed to precarious conditions in prisons. In this framework, social inclusion programs for former convicts are important. In this study, it was investigated the Project Return, developed in the state of Minas Gerais, Brazil, and aimed to reinstate the egress to the formal labor market, via partner organizations. Considering that labor activity plays a central role in the life of these subjects and using as theory, among others, especially the works of Morin, it was sought to understand the meanings attributed to work by former convicts inserted in two organizations with partnership with the Project Return. The methodology adopted was the qualitative research. Twelve former convicts and two HR professionals from the organizations were interviewed and their statements transcribed. The interview material was subjected to content analysis, which led to the creation of six analytical categories for the egresses speeches - work trajectory, life in prison, life post-prison, jobs as egresses, job perception, meanings of the work - and a seventh, the vision of HR professionals. The results show that, paradoxically, despite exercising precarious activities, former convicts reported job satisfaction.

Keywords: Meanings of work, Former convicts, Reintegration into the formal labor market.

As prisões que nos habitam, que nos criam e que mantemos também limitam o nosso olhar e tornam a nossa condição e produção menos amplas...

(Isadora d'Ávila Toledo, 2012)

\section{Introdução}

1 Trabalho baseado na dissertação de mestrado intitulada "O trabalho e seu sentido para egressos do sistema prisional: estudo de uma experiência de reinserção no mercado formal de trabalho", defendida em 2012 para obtenção de título de Mestrado em Psicologia, na Universidade Federal de São João del Rei, financiada pela Coordenação de Aperfeiçoamento de Pessoal de Nível Superior (CAPES). A pesquisa foi avaliada e aprovada pelo Comitê de Ética Envolvendo Seres Humanos (CEPES/UFSJ).

2 Mestre em Psicologia do Trabalho, UFSJ.

3 Doutora em Psicologia Social pela Pontifícia Universidade Católica de São Paulo.

4 Doutora em Psicologia pela Universidade de Paris Norte, Paris XIII. 
O número de detentos no Brasil é alto, abarcando, em dezembro de 2012, mais de 500 mil presos. ${ }^{5}$ Trata-se de um problema social grave, não apenas pela situação precária em que os sujeitos encarcerados se encontram, mas também pelos reflexos ocasionados na segurança pública. Além disso, dados do Conselho Nacional de Justiça (CNJ, 2010c) mostram que 30\% da população carcerária já deveria estar em liberdade, o que não se dá devido à morosidade dos processos em julgamento. ${ }^{6}$

Entre dezembro de 2005 e dezembro de 2009, a população carcerária aumentou de 361.402 para 473.626 pessoas, o que representou um crescimento de 31,05\% em quatro anos. Segundo o Departamento Penitenciário Nacional (DEPEN, 2010), esse percentual contribuiu para o déficit de 194.650 vagas nos presídios brasileiros. Além de onerosa para o Estado - em média, R \$ 1,5 mil mensais por preso (Rossini, 2011) -, a conglomeração de detentos em prisões sem condições para alojá-los evidencia uma infraestrutura deficiente.

Minas Gerais, cujo crescimento da população carcerária teve aumento de 42\% em cinco anos, figura como o segundo estado brasileiro com maior população de detentos. Em dezembro de 2006, o número correspondia a 34.833; já em dezembro de 2010, esse número passou para 46.293 presos (DEPEN, 2010).

Além da condição precária à qual a maioria dos presidiários é submetida, o ambiente prisional parece não contribuir efetivamente para prepará-los para a vida fora da prisão e, tampouco, para a transformação do sujeito que ali se encontra (Barbalho \& Barros, 2010). Assim, a frequente situação de vulnerabilidade antes e depois da privação da liberdade favorece a condição de marginalidade. Um estigma é comumente imputado à população advinda de prisões. Aliada a isso, a trajetória pessoal e ocupacional anterior dos egressos, marcada por renda e escolaridade baixas, além de qualificação profissional precária, contribui para a manutenção da vulnerabilidade social desses sujeitos.

Outra questão importante se refere ao índice de reincidência na infração à lei. Apesar da falta de precisão dos dados quanto ao número de reincidentes, a avaliação dos mutirões carcerários aponta uma parcela significativa de pessoas com mais de um processo nas varas criminais e nas varas de execução penal. Segundo levantamentos, os índices oscilavam entre 60 e 70\%. ${ }^{7}$ Em 2007, cerca de $90 \%$ dos ex-detentos que retornaram à sociedade voltaram a delinquir e, consequentemente, acabaram retornando à prisão (Assis, 2007).

É importante considerar que altas taxas de reincidência repercutem na segurança pública, afetando todos os setores da sociedade. Evidencia-se, pois, a necessidade de planejamento e implementação de programas de reintegração social que atendam à população de forma a facilitar a ampliação de possibilidades para egressos do sistema prisional.

Muitos projetos têm atuado dentro dessa perspectiva. Neste estudo, destaca-se o Projeto Regresso, desenvolvido em Minas Gerais desde 2008 e vinculado ao Programa de Reintegração Social do Egresso do Sistema Prisional (PRESP) da Secretaria de Estado de Defesa Social (SEDS). Pesquisou-se, aqui, o processo de reinserção dos egressos do sistema prisional no mercado formal de trabalho, via organizações parceiras do Projeto Regresso.

Trata-se de uma problemática recente, que dialoga diretamente com os desafios apresentados ao mundo do trabalho atual. Partindo da observação de que a atividade laboral tem função central na vida do sujeito e utilizando como principal embasamento teórico os trabalhos de Morin (2001, 2002, 2004) e Morin, Tonelli e Pliopas (2007), buscou-se, no entrelaçamento de elementos objetivos e subjetivos, compreender os sentidos atribuídos ao trabalho pelos egressos do sistema

5 Dados do Sistema de Informações Penitenciárias (INFOPEN, 2011 e 2014) apontaram que, em 2010, 496.251 pessoas compunham a população carcerária brasileira; em dezembro de 2012, essa população era de 548.003, dos quais 45.540 em Minas Gerais.

6 A situação do sistema carcerário no Brasil passou a ser conhecida melhor após a criação, pelo Departamento Penitenciário Nacional (DEPEN), do INFOPEN, ferramenta que consolida informações a respeito da realidade do sistema penitenciário brasileiro. Utilizada desde 2004, ela contribui para a realização de diagnóstico mais detalhado sobre a população prisional no Brasil.

7 Dados obtidos por meio do projeto Começar de Novo (CNJ, 2010b). 
prisional quando inseridos no mercado formal de trabalho. O conceito de sentido adviria do latim sensus, referindo-se à capacidade de conhecer, analisar e sinalizar, e também de sumo, de origem germânica, referindo-se ao direcionamento tomado pelo sujeito em suas ações. Em uma análise psicológica, o sentido estaria associado à interligação de fatores que conferem equilíbrio aos sistemas e estruturas. Essas definições adotadas por Morin assemelham-se às considerações feitas anteriormente por Frankl (1990), para quem o sentido é concebido como fundamental, uma dádiva a priori, uma motivação primária, e, dessa forma, é constitutivo, uma vez que "ordena, estabiliza, a vida de cada uma das partes integrantes" (p. 60).

A partir da proposta de atualização de conceitos e das contribuições do grupo Work International Research Team - MOW (1987), e de autores como os psiquiatras existencialistas Viktor Frankl (1963) e Irvin Yalom (1980), Morin tem buscado compreender o sentido do trabalho nas organizações, dentro de uma perspectiva de experiências concretas vivenciadas pelos sujeitos. Seus estudos têm contemplado três fontes que estruturam o trabalho na modernidade: a significância, a orientação e a coerência (Morin, 2004). Esses elementos definiriam o sentido do trabalho de tal forma que, ao atribuir ao que realiza um significado positivo, uma direção que o guia e o harmoniza com o seu entorno, o trabalhador torna-se capaz de aplicar suas competências segura e autonomamente, relaciona-se adequadamente com seus colegas, contribui para a sociedade e dá sentido à sua própria vida (Morin, 2001). Por sua vez, o coletivo MOW define o significado de trabalho como um construto psicológico multidimensional e dinâmico, resultante da interação entre variáveis pessoais e ambientais e possuidor de três dimensões básicas: centralidade do trabalho, suas normas sociais e seus resultados valorizados.

Como resultado de pesquisa, Morin (2002) sugere categorias ou dimensões importantes para se avaliar o trabalho. Idealmente, ele deveria ser moralmente aceitável, ser fonte de relações humanas satisfatórias, garantir segurança e autonomia, manter as pessoas ocupadas, dar-lhes tranquilidade e ser eficiente na geração de resultados intrinsecamente satisfatórios.

Além das teorizações e pesquisas de Morin, foram utilizados, neste trabalho, os resultados e os conceitos de Barbalho e Barros (2010), Betiol (2009), Goffman (1961), Pires e Gatti (2006), Seron (2009) e Wacquant (1999), estudiosos das instituições prisionais, do estigma, da importância do trabalho e dos processos de inclusão/exclusão. Noções desenvolvidas por Castel (2008a; 2008b; 2011) auxiliam, também, a pensar sobre o trabalho na sociedade contemporânea e sobre os processos que resultam em configurações laborais perversas. Recentemente, esse sociólogo francês interessouse pela exclusão e marginalização relacionadas ao trabalho. Ele argumenta que, na sociedade, de fato, não há ninguém excluído, mas pessoas mal inseridas, com vínculos sociais instáveis, sujeitos a rupturas. Elas não têm patrimônio, vivem em habitações precárias, sem domicílio fixo, sem perspectiva de trabalho ou desempregadas, sujeitas ao fracasso escolar e à falta de inserção profissional no futuro. Estão à margem, ou melhor, estão incluídas marginalmente, discriminadas, desfiliadas. Desfiliação é, justamente, o conceito que ele criou para descrever essa situação.

Considerando que o trabalho se realiza em um contexto de relações sociais de produção e que ele é fundamental tanto para a construção da identidade do sujeito quanto para seu sentimento de filiação, pertença, reconhecimento e dignidade (Aranha, 2003), importa saber como ele se apresenta ao sujeito egresso do sistema prisional, diante de sua trajetória pessoal e ocupacional. A população advinda do sistema prisional já apresenta, em sua maioria, uma trajetória marcada por desfiliação na qual a escassez de possibilidades de inserção no mercado formal de trabalho é recorrente. Tal escassez é reafirmada, justamente, pela necessidade de políticas públicas de reinserção.

Por isso, busca-se compreender o trabalho e seus sentidos para os egressos do sistema prisional inseridos nas instituições formais via Projeto Regresso e analisar como tem sido o processo de inserção nas organizações investigadas. Efetivamente, quer-se saber se o trabalho ao 
qual esses sujeitos tiveram acesso é realmente central para eles, se tem significado, se os orienta e guia, promove equilíbrio, tranquilidade e harmonia, dá segurança, possibilita autonomia, permite relacionamentos positivos com colegas, contribui para a sociedade, dá sentido à vida, é visto como moralmente aceitável, gera relações e resultados satisfatórios, ocupa os egressos ou, ao contrário, é fator de maior desfiliação e de desvalorização pessoal.

\section{Metodologia: os caminhos percorridos}

Adotou-se a metodologia de pesquisa qualitativa. Foram seguidos os passos propostos por Minayo (2004, pp. 25-26), que identifica um ciclo de pesquisa incluindo uma fase exploratória, o trabalho de campo e o tratamento do material coletado.

$\mathrm{Na}$ fase exploratória, foram buscados programas de reinserção social cuja proposta incluísse egressos do sistema prisional, sujeitos-alvo da pesquisa. Nessa busca, o Projeto Regresso foi identificado. Ele é parceiro de 15 organizações, a maior parte no ramo da construção civil. Em 2010, recebeu 196 egressos que foram encaminhados às organizações parceiras. Dentre esses, 87 foram contratados.

Duas organizações indicadas pelo Projeto Regresso como casos bem sucedidos participaram deste estudo. Uma delas, nomeada $M$ nesta pesquisa, é do ramo da construção civil e tem aproximadamente 1.500 funcionários. Dos 36 egressos do sistema prisional contratados por ela, por intermédio do Projeto Regresso, 14 ainda permaneciam na empresa no momento em que esta pesquisa foi realizada. Dentre eles, nove concordaram em participar deste estudo. Ressalta-se que, entre janeiro de 2010 e julho de 2011, 22 egressos haviam sido desligados, por motivos variados, segundo o profissional de RH da organização, igualmente entrevistado. Os motivos específicos não foram declarados pela organização, sendo apenas possível supor algum deles a partir da fala do representante organizacional, como se verá.

A segunda empresa, nomeada $\mathrm{P}$, situa-se no ramo de artefatos de borracha e tem em torno de 300 funcionários. Dentre eles, 15 egressos foram contratados e três permanecem na empresa, todos tendo participado do estudo. Novamente, não se teve acesso à motivação dos desligamentos ocorridos, embora a questão tenha sido colocada em entrevista realizada com um profissional de RH da empresa. As razões ainda não estão identificadas.

Inicialmente, os critérios estabelecidos para selecionar os sujeitos participantes incluíam tempo de contratação, promoção e tipo de contratação, dentre outros. Após verificar que o número de egressos contratados nas organizações era pequeno, definiu-se que o estudo abarcaria todos os que concordassem em participar dele. Assim, na segunda fase da pesquisa, isto é, no trabalho de campo, foram entrevistados, no total, 12 egressos. Eles receberam nomes fictícios a fim de se preservar suas privacidades. Todos assinaram um Termo de Consentimento Livre e Esclarecido concordando com as condições de sigilo e de utilização dos dados na pesquisa, cujo projeto foi aprovado pelo Conselho de Ética da instituição universitária à qual as autoras são filiadas.

É importante conhecer um pouco mais os sujeitos da pesquisa, descritos a seguir: três egressos estão na faixa etária de 20-30 anos, cinco na de 31-40, dois na de 41-50 e dois na de 51-60 anos, ou seja, estão na faixa de idade da população brasileira economicamente ativa. $O$ tempo em que estiveram presos varia de um ano e cinco meses a doze anos: quatro egressos estiveram presos por menos de cinco anos e sete por cinco ou mais anos, enquanto um não informou precisamente quanto tempo esteve na prisão; ficaram, portanto, presos em idade economicamente ativa. A escolaridade e a qualificação são baixas: três egressos têm formação até o $5^{0}$ ano do ensino fundamental, um tem o ensino fundamental completo, seis o ensino fundamental incompleto e um o ensino médio completo e curso técnico em Contabilidade. 
A faixa salarial está entre $\mathrm{R} \$ 600,00$ a $\mathrm{R} \$ 1.500,00$, dependendo do salário base da função e do acréscimo em benefícios. Em relação ao estado civil, cinco egressos são solteiros, dois têm união estável, quatro são casados e um já teve união estável e, no momento, está separado. O número de filhos varia de zero a cinco, sendo que três egressos não têm filhos, cinco têm um filho, três têm dois e um tem cinco filhos. O número de dependentes varia entre zero e seis. Cinco egressos se declararam evangélicos, dois católicos e os demais parecem não praticar nenhuma religião.

O tempo desde a saída da prisão varia entre um mês e três anos. Três egressos estão em liberdade há menos de um ano, cinco estão em liberdade há mais de um ano, sendo que quatro deles estão até um ano e seis meses, e um a três anos. Oito egressos já cumpriram suas penas, dois estão em prisão domiciliar, um em albergue e um em regime condicional.

Para oito dentre os doze egressos entrevistados, o primeiro trabalho depois que saíram da prisão foi na empresa em que trabalhavam no momento da entrevista, enquanto os outros quatro tiveram trabalhos informais depois da saída da prisão, geralmente junto a algum membro do seu grupo familiar. Assim, todos os egressos entrevistados estavam em seu primeiro emprego formal depois do cumprimento da pena. Ressalta-se, contudo, que apenas para três deles tratava-se do primeiro trabalho formal, uma vez que, antes da prisão, nove haviam trabalhado com carteira assinada. O tempo de permanência na empresa atual variava de uma semana a dois anos, sendo que sete egressos estavam há menos de um ano na empresa e cinco há mais de um ano.

Com o objetivo de compreender o trabalho e seus sentidos para os egressos contratados, foram realizadas entrevistas semiestruturadas. Os dois profissionais de RH das empresas também foram entrevistados, a fim de se conhecer o processo de inserção dos egressos do sistema prisional nas duas organizações parceiras do Projeto Regresso. As entrevistas foram previamente marcadas por telefone e realizadas nas próprias organizações. Com antecedência, solicitou-se uma sala adequada para a realização da pesquisa, de modo a assegurar o sigilo das informações e a preservar a identidade dos entrevistados. Após a leitura e explicação do Termo de Consentimento Livre e Esclarecido, as entrevistas foram gravadas com o consentimento dos entrevistados e, posteriormente, transcritas, ${ }^{8}$ em um processo que consistiu na escuta exaustiva para que as falas dos sujeitos fossem digitalizadas de forma fidedigna. Logo após cada visita às empresas, as impressões, reflexões e situações ocorridas em campo foram anotadas. A utilização desse diário de campo contribuiu para a identificação de algumas categorias de estudo, enriquecendo, assim, a análise do objeto investigado.

As entrevistas foram analisadas segundo a proposta de Bardin (2010), que preconiza uma análise de conteúdo feita em três momentos: pré-análise, exploração do material e tratamento dos resultados. Foram consideradas também as contribuições de Minayo (2004), que sugere, para a fase de tratamento do material colhido no campo, as seguintes etapas: ordenação, classificação e análise propriamente dita.

A seguir são apresentados os resultados da última fase do ciclo da pesquisa, as análises finais das entrevistas. As categorias que organizam a apresentação foram estabelecidas conforme Bardin (2010), após a leitura atenta das transcrições e a consideração das notas de diário de campo.

\section{Síntese dos resultados}

As primeiras cinco categorias geradas pela análise do conteúdo ("Trajetória de trabalho", "Vida na prisão", "Vida pós-prisão", "Primeiro trabalho como egresso do sistema prisional" e "O que o trabalho representa para o egresso") trazem informações pertinentes para a análise da sexta

8 Utilizou-se um gravador Panasonic RR-US450 e, para as transcrições, o programa Voice Editing 2.00 Premium Edition. 
categoria, "Os sentidos do trabalho", que é a questão central desta pesquisa. Uma sétima categoria - "A visão dos profissionais de Recursos Humanos e das organizações" - auxilia na resposta às outras indagações da pesquisa. Na medida em que esses resultados são apresentados, sempre que pertinente, eles são contrapostos ao referencial teórico adotado.

\section{Trajetória de trabalho:}

Observou-se que todos os egressos entrevistados nesta pesquisa exerceram atividades laborais na infância, o que pode sugerir uma relação entre trabalho infantil e criminalidade. Porém, o número de entrevistados e a opção pela metodologia qualitativa não permitem esse tipo de generalização. $\mathrm{O}$ resultado observado sugere, no entanto, a necessidade de pesquisas futuras sobre a relação antevista. De toda forma, de acordo com convenções internacionais (OIT, 2001a, 2001b), pode-se afirmar que todos os egressos que participaram deste estudo viveram situações de trabalho irregulares na infância e na adolescência. $\mathrm{O}$ relato de W. exemplifica esse fato:

Eu simplesmente comecei, desde pequeno. Já fui carregador de sacolão, já trabalhei de carregador, já trabalhei de vigiar, lavador de carro, já catei latinha, já catei esterco. Trabalhei de marceneiro, pintura, metalúrgica, principalmente na área de industrial de carros, e esse tipo de máquinas que eu mexo aqui na empresa agora. Fiquei um ano como marceneiro, um ano como lanterneiro lá perto de casa, um ano como secretário administrativo quando trabalhava na prefeitura. Depois dois anos e meio como metalúrgico, operador de processo industrial. (...) Meu primeiro trabalho de carteira assinada foi na marcenaria, o segundo foi o estágio em administração e o terceiro foi na F. Foi assim...

\section{Vida na prisão:}

Com relação à vida na prisão, os egressos certamente passaram pelos problemas enumerados por Wacquant (1999), decorrentes de uma estrutura deficiente para abrigá-los, superlotação, agrupamento de pessoas sem diferenciação por crimes, humilhação, sofrimento e motins, dentre outros. Passaram, também, possivelmente, pela despersonalização característica das instituições totais (Goffman, 1961). Nas entrevistas desta pesquisa, realizadas no momento em que ressignificavam essas experiências, os egressos demonstraram dificuldades para falar sobre elas. Alguns as veem como um freio importante que lhes permitiu sair da criminalidade, outros se calam. Todos criam estratégias para negligenciar esse momento de sua história, seja pelo silêncio ou pelo desejo manifesto de esquecimento desse período da vida. Três falas dos egressos trazem descrições do que pensam sobre a vida na prisão:

Cadeia não regenera ninguém. Você entra lá aprendendo a roubar uma agulha, você sai aprendendo a roubar um avião. Não regenera ninguém. É uma máquina de criar monstros. Pra mim é. Talvez cada um tem uma opinião diferente. Eu tenho a minha. (F.)

A pessoa quando é preso, na verdade só pensa. Tempo pra pensar é o que mais tem. Sozinho, quer ver seus acertos, onde que eu errei, o que eu fiz. Você começa a fazer um retrospecto da sua vida. (A.)

E lá é tudo na hora certa, comida na hora certa. Então, você não sabe se você tomou café de manhã, se comeu um pão, pressão terrível. Entendeu? É assim porque o sistema prisional é meio confuso. O tempo que você perde da sua vida, o tempo que você perde ali preso, é para nunca mais. (C.M.) 


\section{Vida pós-prisão:}

Após a saída da prisão, além dos receios relacionados à vida profissional, a dimensão afetiva também se encontrava afetada. Os egressos apontaram os desafios enfrentados ao saírem: viveram dificuldades de se reintegrarem, perderam a possibilidade de obterem o atestado de bons antecedentes requerido nos processos seletivos para trabalharem, as relações de parentesco e vizinhança ficaram estremecidas. Vivem, assim, as desfiliações mencionadas por Castel (2008a, 2008b), tornando-se sujeitos vulneráveis devido as suas trajetórias de rupturas com a sociedade. Eles têm escolaridade e qualificação baixas, não chegaram à $8^{\mathfrak{a}}$ série do ensino fundamental, o que lhes restringe as oportunidades de trabalho. Essa conjuntura facilita a discriminação desses sujeitos vítimas da desfiliação. Vejam-se os exemplos:

Muitas portas se fecharam. Igual eu tive altos lugares que eu fui aí, me pediram atestado de bons antecedentes. Perdi as vagas de emprego. Nosso Deus. Me volto lá trás e falo ‘Como que eu fui burro. Jogar tudo fora assim. Comprometi a vida toda'. Hoje eu tento consertar, mas sempre vai ter isso aí. Sempre. Isso aí não tem como negar não. Onde eu chegar e eles souberam que eu tive essa passagem aí, eles já me eliminam. (Wn.)

Pra mim é tudo. Meu sonho toda a vida é trabalhar mesmo. Caiu lá dentro fica louco com uma oportunidade. Não esperava ter uma oportunidade igual eu estou tendo. Antigamente era difícil. Chegava em um lugar, a porta tava fechada mesmo. E hoje já abriu as portas. Uma firma até me chamou aí já. (J.L.)

Nesse contexto, entre alguns egressos, identifica-se frustração e desejo de retorno à criminalidade. Todos reconhecem o estigma de que são vítimas, seja abertamente, seja denegando a existência da discriminação. Barbalho e Barros (2010) já evidenciaram que o sujeito estigmatizado apresenta maior probabilidade de retorno às atividades ilícitas, já que nelas encontra possibilidades de atuação. Alvo de discriminação em muitas ocasiões, o egresso pode encontrar-se mais vulnerável se não encontra apoio. Pode, assim, alimentar o ciclo criminalidade/punição apresentado por Pires e Gatti (2006), como mostram os exemplos:

Discriminado, desprezado. Sentia humilhado. Virava pra mim e pensava: 'Você apronta, você faz e acontece, você é preso, você tirava a paz da sociedade, um peso, (...) você saiu, você tenta fazer o que a sociedade faz, o que a sociedade diz que é certo, e eles não te aceitam, não te dão oportunidade'. Porque discrimina o crime, mas não dá oportunidade, vai empurrando o cara de novo pro crime. Tentei demais, mas nenhum lugar me chamou. Voltei e fiz coisa errada de novo. Voltei. (F.)

Aqui, qualquer lugar. Todo o lado que você vai é discriminado. A pessoa que saiu e mudou, também é. É discriminado do mesmo jeito, e dá para ver pelo jeito que a pessoa te trata. Você chega pra resolver uma coisa, a pessoa já vai, mesmo que não saia da sua frente. Vai atender uma pessoa primeiro que você... Só que aí na hora das entrevistas e tal, aí sempre era barrado, e aí pelo motivo deles não aceitarem e tal, por causa da passagem, e aí foi assim. (C.C.)

Seron (2009) indica que o grupo familiar é considerado essencial para o processo de reintegração social. Betiol (2009) lembra que a importância atribuída à família é central tanto na amostra parisiense que estudou como na paulista. No presente estudo, também, a família surge garantindo condições de suporte e aceitação aos egressos. Ela é uma motivação para que eles gerem 
renda para a sobrevivência dela, ou seja, um motivo para que trabalhem na legalidade. A família é, assim, um elemento que atua no afastamento de práticas ilícitas. O egresso quer preservá-la do sofrimento procedente da sua vida na criminalidade. As falas que se seguem ilustram o vínculo com as famílias:

Eu falo de família. Eu não, esse vínculo familiar, nem com os meus filhos eu não tinha. Eu ficava mais fora de casa. Chegava em casa, era coisa de minuto, chegava, olhava e saía de novo. Agora não. Agora já é diferente. Agora eu já tenho um vínculo familiar. Com minha família, meus filhos, com minha noiva, com minha família toda. Agora eu já tenho, mas antigamente eu não tinha não. (E.)

Ah, me sinto em paz comigo mesmo, tranquilo, que eu vou poder ir pra casa de tarde, ver minha família normalmente e tal. (G.)

Acabou que o trabalho é até de questão familiar. Acabou que a minha família está mais perto de mim. Me ajuda mais, preocupa. (Gl.)

Minha família, minha esposa, deu todo o apoio, desde o momento que eu fui preso, até sair e tudo. Porque se eu não tivesse esse apoio, eu não sei se eu estaria aqui nesse momento não. (G.)

\section{Primeiro trabalho como egresso do sistema prisional e o trabalho que realiza atualmente:}

Com efeito, na vida pós-prisão, alguns egressos encontraram seu primeiro trabalho por meio de indicação do grupo familiar. Para outros, amigos e o Projeto Regresso foram fundamentais. Isso evidencia a importância dos grupos de apoio, o papel relevante do Projeto Regresso, por possibilitar uma vaga no mercado de trabalho, anteriormente inviável aos egressos devido ao registro de passagem na prisão:

Estava trabalhando com meu tio, entendeu? Trabalhei com ele um mês e pouco, de servente também. Aí eu vim pra cá. Aí o meu tio conheceu um rapaz que trabalhava aqui. (Gl.)

É, os antes foram um bico. Eu estava lá no C., estava num negócio de cimento lá, mas aqui é uma coisa mais... É meu primeiro trabalho de carteira assinada. (Wn.)

É meu primeiro trabalho. Depois que eu saí da prisão eu fiquei uns oito meses procurando emprego. (G.)

É, o primeiro. Eu fui saindo da prisão e fui vindo pra cá. Eu tenho um cunhado aqui que me encaminhou. Ele trabalha aqui e conhece o encarregado. Aí ele pediu pra eu vim aí. (J.L.)

\section{O que o trabalho representa para o egresso:}

Como no estudo de Seron (2009), que mostrou que a remuneração viabiliza condições para que os egressos se tornem "consumidores ativos" (p. 16), esta investigação indicou que o trabalho é muito importante na vida do egresso. A geração de renda é um fator central para que ele realize o desejo de possuir bens e de ascender socialmente, uma das motivações que, anteriormente, o levara ao crime. Assim, os resultados deste estudo confirmam os achados de Pires e Gati (2006) e de Barbalho e Barros (2010): 
Porque eu estou recuperando agora que eu trabalho, que no dia 30 pego o meu dinheiro. Tenho 21 anos. Quero comprar uma coisa pra mim, ir no shopping e comprar um monte de trem, ah agora eu quero uma coisa, ta lá, tranquilo. Os vizinhos me veem de outro jeito. Bom demais. (F.)

Eu queria mais dinheiro, mais dinheiro, e minha vida era só pensar em dinheiro. Então por isso que eu não queria saber do vínculo. Queria roupa, sair, viajar... para gastar, acaba que era besteira. Ajudar em casa, até que eu ajudava. Chegava e dava o dinheiro pra minha mãe, mas não saía. Fiz minha casa, ajudei minha mãe na casa dela também, mas minha intenção era mais essa, entendeu? (Gl.)

Ambição de ter dinheiro, de melhorar de vida. Mas hoje eu carrego ainda comigo essa ambição ainda, com certeza. Carrego comigo, mas eu acho que essa ambição eu posso sustentar ela de uma forma correta. (G.)

\section{Os sentidos do trabalho:}

Os resultados encontrados nesta investigação assemelham-se aos da pesquisa realizada por Morin (2002) em quatro das seis categorias identificadas pela autora: o trabalho é moralmente aceitável, é fonte de relações humanas satisfatórias, garante segurança e autonomia e é o que mantêm os egressos ocupados. $\mathrm{O}$ trabalho apresenta-se a eles segundo as dimensões de ocupação, relacionamentos, tranquilidade, sentido moral e sobrevivência. Essa última dimensão apresentase equivalente à que garante segurança e autonomia para Morin, ou seja, ela é aquela que traz benefícios, sustento, emprego e capacidade de se utilizar as habilidades próprias a fim de solucionar problemas e tomar decisões.

Com relação ao sentido moral do trabalho, eles falam:

O trabalho dignifica o homem. Mesmo você ganhando mixaria. Porque você tem mais compromisso com as coisas. (...) Quantas pessoas que roubam e quantas que você vê levantando cedo para trabalhar? A maioria. Tudo o que a maioria faz. A minoria tá roubando. Assim em vista de quem trabalha, então vão correr pelo certo. Tentei a vida inteira correndo pelo errado e não deu em nada. (E.)

Vida normal, vida de trabalhar, de não carregar o peso nas costas, melhor dizer assim. (G.P.)

No que diz respeito ao trabalho como fonte de relações humanas satisfatórias eles assim se expressaram:

Sabe aquela felicidade espontânea, de você chegar e você sorrir e brincar com seus companheiros de trabalho, naturalmente. E quando eu começo a trabalhar aqui na empresa, (...) aí que eu vejo que o pessoal tá reconhecendo o meu trabalho, reconhece o meu esforço, reconhece que eu estou me esforçando, mas superando a mim mesmo. (W.)

No começo eu não pensava em ficar aqui não. Eu só pensava em dar uma sossegada, tranquilizar minha família um pouco e continuar ganhando meu dinheiro do jeito que eu ganhava no centro da cidade. Só que as coisas mudaram. Mudaram de repente. Eu me apeguei a eles, me apeguei à equipe que eu trabalhava à noite. $\mathrm{O}$ pessoal me acolheu bem, e fui me afastando, fui me afastando, e cada vez trabalhando mais, me esforçando mais e fui 
relembrando daquilo que eu gosto de fazer. (...) Porque às vezes muitas pessoas entram com a intenção de sossegar, só que às vezes o ambiente, as pessoas cativam ela e isso transforma a pessoa. $\mathrm{O}$ que me transformou na realidade foi o meu ambiente de trabalho, a equipe que eu trabalho, o pessoal que me acolheu bem, os amigos que eu fiz, a minha família. Isso aí me acendeu uma chama de volta (...), restaurou o meu espírito. (W.)

O trabalho como algo que os mantêm ocupados se evidencia em falas como:

Porque eu ocupei mais a minha mente, eu me dediquei mais ao meu trabalho, à minha família e não tive tempo pra pensar coisas erradas igual eu pensava. (...) Existe um ditado que diz que cabeça vazia é oficina do demônio, e é verdade. (Wn.)

Gosto. Serviço pra mim a gente não pode ficar é parado, porque a gente fica parado, a gente pensa muita coisa ruim. Eu mesmo não penso muita coisa ruim. Eu fico assim desesperado. "Ah, meu Deus, eu tenho que trabalhar". Não aguento ficar parado. (J.R.)

Quanto à tranquilidade:

O trabalho? Ele é como se fosse o recomeço. Entendeu? Porque pra mim o primeiro ponto foi minha família e o principal de todos foi Deus. Então, isso foi me fortalecendo a cada dia, me dando mais vontade a cada dia de ir batalhar, de batalhar e de batalhar mais, de lembrar que eu sentia uma coisa que eu não sentia há muito tempo: tranquilidade. (W.)

Mudou muita coisa. (...) Até meu jeito antigamente no envolvimento com a criminalidade, a minha vida era muito tensa. Ficava preocupado com os outros que queriam me matar, mas não é assim mais. Agora já posso trabalhar, ir para casa tranquilo. Antigamente não, era muita correria, não parava em casa, dava atenção a ninguém, agora não. Agora eu já dou mais atenção às pessoas. (Gl.)

\section{Quanto à sobrevivência:}

Porque eu trabalhando, eu sei quanto que eu tenho, o dia que eu vou ter, e eu sei que eu tenho ele. Então eu tenho um compromisso. Eu sei o que eu já tenho, o que eu posso pagar tanto, o que eu posso comprar, sei que eu vou ter dinheiro pra pagar naquele dia. (E.)

[O trabalho é] tudo. Eu estou reconstruindo minha vida através do trabalho. Eu arrumei meu quarto, comprei cama nova, muitas coisas. (G.P.)

Hoje eu acho que o trabalho é minha base. Minha base de tudo, principalmente financeira, o que me ajuda aí no dia a dia. (C.M.)

Outra categoria identificada no estudo de Morin (2002) - o trabalho é eficiente e gera resultados - não foi identificada com clareza nas falas dos egressos. Essa constatação pode estar relacionada às diferenças entre os entrevistados desta pesquisa e os de Morin, administradores e pós-graduados em administração que possuem outras qualificações e expectativas devido à trajetória ocupacional e à posição social que ocupam.

Finalmente, para os entrevistados por Morin (2002), a categoria 'o trabalho é intrinsecamente satisfatório’ refere-se à satisfação obtida com a realização de uma função que possibilita desenvolvimento tanto na dimensão organizacional quanto na individual. Nesta pesquisa, diferentemente, foi possível 
perceber que a satisfação dos egressos de trabalhar nas organizações, dentre outros fatores, está atrelada às amizades e relações construídas com os colegas de trabalho, como se apreende na fala:

Sabe aquela felicidade espontânea, de você chegar e você sorrir e brincar com seus companheiros de trabalho, naturalmente. E quando eu começo a trabalhar aqui na empresa, quando eu venho pra cá, aí que eu vejo que o pessoal ta reconhecendo o meu trabalho, reconhece o meu esforço, reconhece que eu estou me esforçando, mas superando a mim mesmo. (W.)

\section{A visão dos profissionais de Recursos Humanos e das organizações:}

Como recurso complementar para cumprir os objetivos da pesquisa, buscou-se conhecer o processo de reinserção social nas organizações contratadoras. Verificou-se, nas entrevistas com os profissionais de RH que a adesão das duas organizações ao Projeto Regresso basicamente ocorreu devido à demanda de mão de obra no mercado de trabalho e ao desejo de desenvolverem um trabalho social, o que está exemplificado nas falas:

$\mathrm{Na}$ verdade, a nossa única expectativa mesmo é que eles fossem mais comprometidos e, também, porque a gente tem um apagão de mão de obra. Tanto que desde o ano passado eu não consigo completar o quadro de funcionários. Não consigo completar homens. (P.)

Porque a gente espera que essas pessoas, já que procuram tanto uma nova oportunidade, que eles agarrassem onde elas estivessem. Então assim, serem mais dedicados, comprometidos. E em alguns casos a gente pode conseguir isso, em outros não. (P.)

Desse modo, considera-se que o perfil dos egressos atende às necessidades das organizações nesse momento. O perfil requerido é o de homens com força física, que não necessariamente precisam ter qualificação ou experiência. $O$ processo de recrutamento e seleção nas organizações pesquisadas é feito por meio da triagem realizada pelo Projeto Regresso, encaminhamento dos selecionados para as organizações parceiras, teste operacional da função e entrevista psicológica.

Mas a gente não exige nada. A gente não exige experiência nenhuma. A única coisa que precisa é ser alfabetizado para poder preencher a ficha de produção. E não dá pra ser uma pessoa que não tem como a gente selecionar para o trabalho. Tem coisa que é preciso fazer. Então a gente contratou homens por isso. Por força física mesmo. (P.)

O processo seletivo realizado em uma das organizações é restrito aos egressos: a entrevista psicológica é exclusiva para eles e visa avaliar suas motivações para o trabalho. A decisão por esse procedimento incita questionamentos a respeito do maior investimento em seleção do que em treinamento e desenvolvimento, além de sugerir discriminação frente a não-egressos.

Porque os demais profissionais de obra, eles não fazem avaliação aqui no RH. E os egressos, eles passam aqui, a gente não faz avaliação psicológica deles, mas a gente faz entrevista psicológica, com o intuito mesmo de rastrear um pouco desse perfil e identificar a adaptação dele nesse processo de obra. Depois eles passam por uma avaliação técnica dentro da própria obra. Muitos deles já têm experiência, aí eles são direcionados para os cargos, outros não. (M.)

O processo de treinamento é operacional e tem foco no desempenho da função. Há ainda treinamento em procedimentos de segurança, entre outros, que são repassados a todos os 
funcionários como forma de integração quando ingressam no trabalho. Não tem sido realizado nenhum tipo de acompanhamento específico de egressos pelos profissionais das organizações. Não há escuta diferenciada, orientação e/ou avaliação dos egressos que estão inseridos nas organizações.

Eu faço treinamento de integração: sobre benefícios, segurança do trabalho e de equipamento de segurança, e depois a comunidade faz o treinamento sobre qualidade. (P.)

Não, nós não fazemos acompanhamento formalizado. A não ser uma pessoa que está dando problema. Está faltando demais, está apresentando muito atestado, está enrolando no serviço, aí nós vamos chamar pra um acompanhamento. (M.)

Existe um acordo entre organizações parceiras e o Núcleo do Projeto Regresso que determina que os profissionais do Núcleo podem ser acionados caso seja necessário. No entanto, há uma lacuna nessa conexão e o que tem se constatado é que não têm sido desenvolvidas ações de integração específicas para os egressos. As organizações argumentam que esse procedimento pode atuar como uma forma de exclusão e diferenciação. O Projeto tem atuado pouco depois que os egressos são encaminhados. Talvez, o grande volume de trabalho das empresas e do Projeto seja a justificativa para essa situação; ou, talvez, a razão seja a falta de definição de tarefas e responsabilidades a respeito do processo de reinserção social de egressos.

Foi possível averiguar a falta tanto de acompanhamento sistematizado quanto de sensibilização das chefias e colegas de trabalho para receberem e colaborarem na reinserção dos egressos. Ao contrário, omite-se o fato de eles serem egressos. Questiona-se, aqui, a necessidade ou não de maior investimento em ações de integração e desenvolvimento para os egressos, considerando-se a forma como entram nas organizações e os objetivos das empresas. Indaga-se, também, sobre as consequências da ausência de ações específicas, e sugere-se a realização de outros estudos sobre essa temática.

Eu não faço acompanhamento dos meus outros funcionários. Porque que ele é egresso, aí eu vou ter que acompanhar? (M.)

Não, ele participa junto com todos os outros. A gente tem um volume de admissão enorme. Então se está entrando 10 e entra um egresso, não interessa, ele entra junto com aquele grupo, faz o treinamento de integração, participa de todas as etapas, igual ele é feito pra todo mundo. Em momento nenhum a gente expõe que ele é egresso. A gente tenta manter isso da forma mais sigilosa possível. (M.)

A gente não sabia bem o que fazer. Principalmente quando eles começaram a contar para os colegas. Assim, a vizinhança veio falar com a gente 'Vocês tão colocando ex-presidiários aí pra trabalhar. E a gente como fica? A gente está correndo risco'. Então é bem cheio desse preconceito. (P.)

Apesar de não haver avaliações sistematizadas sobre a inserção de egressos nas organizações, algumas facilidades e dificuldades podem ser indicadas. Como parte da primeira categoria, o perfil dos egressos se apresenta como uma vantagem na contratação para as organizações, por se esperar que eles, devido à passagem pela prisão, valorizem mais a oportunidade do que funcionários que não têm a mesma restrição de oportunidades. Assim, são considerados mais comprometidos.

Eu acho que uma facilidade de quando você pega um egresso e que ele já sabe o que é ficar preso. O que é esse mundo da prisão e, se ele quer realmente mudar de vida, ele vem com um espírito mesmo 
de dedicação muito forte, então ele faz o que dá e o que não dá pra atingir o seu objetivo no emprego. Então nós temos vários casos assim, de que as pessoas são gratas à empresa e fazem de tudo pra empresa pra poder ter, pra conseguir se manter ali, não voltar pro mundo do crime. Eles valorizam mais do que outros (...). Então acho que isso é um facilitador. Mas ele tem que querer. Então é muito particular isso. $\mathrm{O}$ facilitador do egresso é isso. Quando ele vem com esse espírito, nossa, pode confiar demais. (M.)

São pessoas que têm boa vontade de trabalhar, que já sofreram muito. Porque imagino que não deve ser fácil ficar detido. São pessoas que dão valor, na maior parte das vezes. (P.)

Dificuldades têm acontecido especialmente na etapa de recrutamento, pois muitos se desviam na transição prisão-organização. Os motivos desse volume de perda de egressos ainda não é identificado, mas suspeita-se que a falta de informação, de acompanhamento específico e de autoconfiança sejam fatores que influenciam. Sabendo das limitações de tempo e recursos do Projeto e das parcerias estabelecidas, identifica-se a necessidade de um trabalho mais estruturado e sistematizado entre ambos.

A gente disponibiliza uma vaga, a gente fica semana esperando aparecer, sendo encaminhado pelo Núcleo, porque as pessoas falam que vêm e não vêm, ou eles vêm, mas depois não têm interesse. Então eu acho que isso é o grande dificultador. Eu não sei muito bem como é que funciona esse encaminhamento, mas a impressão que eu tenho é que ele sai da prisão e dispersa. (M.)

E na verdade foi difícil para P. conseguir encontrar mão de obra que tivesse interessada ao trabalho. (P.)

As organizações não mantêm dados atualizados a respeito do número de egressos que são desligados do trabalho. Assim também acontece no Projeto Regresso, por motivos de troca de profissionais e do seu pouco tempo de vigência. Acrescenta-se entre as dificuldades apontadas que, ao longo do processo de reinserção, muitos retornam à criminalidade, somando-se ao grande número de reincidentes.

\section{Considerações finais}

Os resultados da pesquisa aqui apresentados permitiram apreender sentidos do trabalho formal para egressos do sistema prisional atendidos por políticas públicas, especificamente pelo Projeto Regresso. Paradoxalmente, embora as atividades laborais oferecidas a eles não utilizem as competências que eles trazem, não lhes confiram qualquer autonomia nem garantam condições mínimas de inserção social e segurança, esses sujeitos relataram satisfação com o trabalho. Nos termos de Morin (2001, 2002, 2004) e Morin, Tonelli e Pliopas (2007), pode-se dizer que os egressos se apresentam como participantes de um trabalho significativo, moralmente aceitável, fonte de relações humanas satisfatórias. Além disso, relatam sentirem-se orientados, guiados, ocupados em atividade que contribui positivamente para o bem estar da sociedade, em situação de equilíbrio, harmonia, tranquilidade e segurança. Essa satisfação está permeada pela gratidão à oportunidade que lhes foi oferecida, como eles próprios relatam e como igualmente sugerem os profissionais de RH das duas empresas pesquisadas.

Por outro lado, dadas às condições da pesquisa, que foi realizada no próprio local de trabalho, junto a uma entrevistadora abertamente conhecedora das condições de ex-presidiários dos 
entrevistados, pode-se afirmar que os egressos tiveram receio em posicionar-se de outra maneira. Em muitos momentos, foi possível identificar contradições nas falas deles o que permite questionar o vínculo "positivo" estabelecido entre eles e as organizações: "É meu primeiro trabalho. Depois que eu saí da prisão eu fiquei uns oito meses procurando emprego"; "Na verdade era a que tinha, era a vaga que tinha...”. De fato, as oportunidades de trabalho de recém-libertos são restritas devido às exigências do atestado de bons antecedentes, em si um instrumento de estigmatização e de segregação social. Outros resultados da pesquisa mostram igualmente características que reduzem a empregabilidade dos ex-detentos: além de terem sido submetidos a trabalho infantil, eles são pessoas de baixa escolaridade e conscientes do estigma que carregam devido à prisão. Foram excluídos da sociedade na infância (ao exercerem o trabalho infantil), no encarceramento e mantêm-se ainda prisioneiros, como atestam suas falas frequentemente estereotipadas.

Dessa forma, é possível afirmar que a pesquisa confirmou os resultados de Seron (2009), que apontaram egressos submetendo-se a trabalhos precários, pouco especializados e mal remunerados que visam primariamente a sobrevivência e não a realização pessoal ou a satisfação. Pois, de fato, eles realizam nas empresas P. e M. trabalhos precários e parecem saber que essa experiência é praticamente a única oportunidade que lhes é apresentada de realizarem trabalho lícito e, também, a única chance de afirmarem autorrealização e satisfação. Não apenas eles, mas também o próprio Projeto Regresso e as empresas parceiras apresentam limitações. $\mathrm{O}$ projeto vê-se frente à grande dispersão de egressos, assim que saem da prisão. Além disso, o número de contratações é pequeno em relação ao número de encaminhamentos (em 2011, 87 em 196, menos da metade). As duas organizações confrontam-se ainda com a grande rotatividade dos contratados: continuaram na empresa M. 14 dos 36 encaminhados e, na empresa P., três entre 15. Aos poucos, os egressos se vão sem que fiquem registros de suas passagens. Talvez estejam engrossando a leva de reincidentes no crime.

As empresas parceiras do Projeto Regresso não parecem estar bastante sintonizadas em termos de posturas e ações com o programa de reinserção. Não apenas há procedimentos discriminativos no processo de admissão, como a entrevista psicológica que tem por objetivo conhecer a motivação para o trabalho, aplicada apenas aos egressos e não aos outros trabalhadores da empresa, mas também as organizações têm informações apenas gerais sobre o processo de reinserção dos egressos e sobre a Lei de Execução Penal que regulamenta que egressos têm direito a acompanhamento por um ano ou período de prova. Não há, nas empresas, qualquer acompanhamento, treinamento ou desenvolvimento voltado a egressos. Além disso, os profissionais de RH entrevistados receiam ainda os impactos negativos da entrada de ex-presidiários para a empresa, e sujeitam-se a pressões da vizinhança e de alguns de seus funcionários que se posicionam contra essa entrada. Porém, estão satisfeitos com o acolhimento positivo por parte dos colegas de trabalho, visto como um diferencial no processo de reinserção. O comprometimento dos egressos foi também avaliado positivamente pelos profissionais que supõem que, por causa das oportunidades restritas de trabalho para exdetentos, eles são necessariamente comprometidos. E isso apesar das atividades precárias, pouco desafiantes e baixamente remuneradas.

Na conceituação de Castel (2008), resulta, para os egressos, a desfiliação, que não implica ausência de vínculos sociais, mas relações distantes de centros de decisão, distendidas e vulneráveis. Machado (2013), em uma revisão desta pesquisa, resume a situação institucional encontrada:

A política do Projeto Regresso (atenção à ambiguidade desse nome) mal toca o fundo da questão: as empresas não sabem muito bem o que fazer com os egressos, negam suas histórias particulares quando camuflam que são egressos, os discriminam quando os submetem a entrevistas psicológicas, descumprem a lei quando não promovem o acompanhamento de seus desenvolvimentos. Penso que buscam ajudá-los, mas sem saber como, tornam-se agentes de novos aprisionamentos, desfiliações, frustrações e outros danos psicológicos (p. 42). 
Esses resultados indicam a necessidade de se introduzirem, nas organizações, políticas efetivas de diversidade e responsabilidade social. No caso dos funcionários da construção civil, entre os quais se verifica grande rotatividade, poderiam ser desenvolvidas metodologias apropriadas e feitos investimentos adequados dirigidos à melhoria na qualidade de vida desses trabalhadores.

Ressaltam-se, entre as limitações desta pesquisa, o número limitado de egressos, devido às dificuldades de acesso às organizações e ao tempo relativamente curto de implementação do Projeto Regresso. Uma pesquisa com dados qualitativos e quantitativos seria interessante para essa temática, pois haveria mais informações e dados passíveis de serem generalizados.

\section{Referências}

Barbalho, L. A. \& Barros, A. V. (2010). O lugar do trabalho na vida do egresso do sistema prisional: um estudo de caso. Gerais: Revista Interinstitucional de Psicologia, 3(2), 198-212.

Betiol, M. I. S. (2009). Os "sentidos" do trabalho em duas visões: São Paulo e Paris. GVpesquisa, 109(3). Recuperado em 3 de janeiro de 2012, de http://bibliotecadigital.fgv.br/dspace/handle/10438/3099

Castel, R. (2008a). A discriminação negativa. Petrópolis, RJ: Vozes.

Castel, R. (2008b). As metamorfoses da questão social (3a ed.). Petrópolis, RJ: Vozes.

Castel, R. (2011). As armadilhas da exclusão. In R. Castel, L. E. W.Wanderley \& M. Belfiore-Wanderley. Desigualdade e a questão social (pp. 21-54). São Paulo: EDUC.

Goffman, E. (1961). Manicômios, prisões e conventos. São Paulo: Editora Perspectiva.

Machado, M. N. M. (2013). Violência, Políticas Públicas, Minas Gerais. In I. F. Ferrari \& J. O. Moreira. Psicanálise e violência: sociedade, juventude e literatura (pp. 35-46). Curitiba: CRV.

Meaning of Work International Research Team - MOW (1987). The meaning of working. London: Academic Press.

Minayo, M.C. S. (2004). Ciência, técnica e arte: o desafio da pesquisa social. In M. C. S. Minayo, S. F. Deslandes,O. Cruz Neto \& R. Gomes. Pesquisa social: Teoria, Método e criatividade (pp. 9-29). (23o ed.). Petrópolis, RJ: Vozes.

Morin, E. M. (2001). Os sentidos do trabalho. Revista de Administração de Empresas -RAE, (3), 18-19.

Morin, E. M. (2002, agosto/setembro/outubro). Fator Humano: os sentidos do trabalho. Revista de Administração de Empresas - RAE, 1(1).

Morin, E. M. (2004). The meaning of work in modern times. Conference. $10^{\text {th }}$ Congress on Human Resources Management, Rio de Janeiro, Brazil, August, 20

Morin, E. M., Tonelli, M. J. \& Pliopas, A. L. V. (2007). O trabalho e seus sentidos. Psicologia e Sociedade, 19 (Edição Especial 1), 47-56.

Pires A. A. \& Gati, T. H. (2006). A reinserção social e os egressos do sistema prisional por meio de políticas públicas, da educação, do trabalho e da comunidade. Inclusão Social, 1(2), 58-65.

Seron, P. C. (2009). Nos difíceis caminhos da liberdade: estudo sobre o papel do trabalho na vida de egressos do sistema prisional. Tese de Doutorado, Instituto de Psicologia, Universidade de São Paulo, São Paulo, Brasil.

Wacquant, L. (1999). As prisões da Miséria. Versão digitalizada: Sabotagem.

\section{Endereço para correspondência}

isadoradtoledo@gmail.com,flaval@superig.com.br,

marilianmm@gmail.com
Recebido em: 01/05/2013

Revisado em: 11/04/2014

Aprovado em: 16/04/2014 